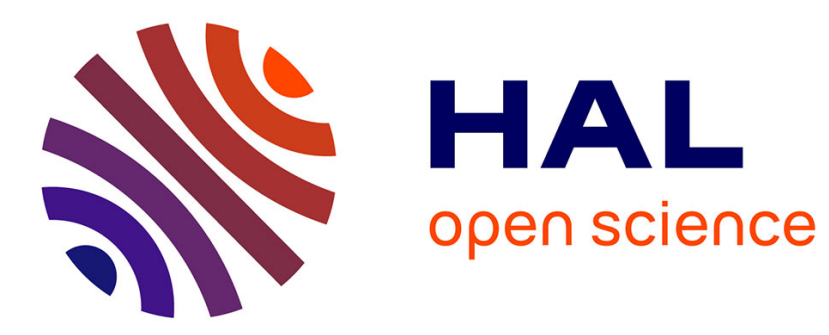

\title{
Complex thermal evolution of size-stabilized tetragonal zirconia
}

Monica Dapiaggi, Filippo Maglia, Ilenia Tredici, Beatrice Maroni, Giulio Borghini, Umberto Anselmi Tamburini

\section{- To cite this version:}

Monica Dapiaggi, Filippo Maglia, Ilenia Tredici, Beatrice Maroni, Giulio Borghini, et al.. Complex thermal evolution of size-stabilized tetragonal zirconia. Journal of Physics and Chemistry of Solids, 2010, 71 (8), pp.1038. 10.1016/j.jpcs.2010.03.002 . hal-00661919

\section{HAL Id: hal-00661919 \\ https://hal.science/hal-00661919}

Submitted on 21 Jan 2012

HAL is a multi-disciplinary open access archive for the deposit and dissemination of scientific research documents, whether they are published or not. The documents may come from teaching and research institutions in France or abroad, or from public or private research centers.
L'archive ouverte pluridisciplinaire HAL, est destinée au dépôt et à la diffusion de documents scientifiques de niveau recherche, publiés ou non, émanant des établissements d'enseignement et de recherche français ou étrangers, des laboratoires publics ou privés. 


\section{Author's Accepted Manuscript}

Complex thermal evolution of size-stabilized tetragonal zirconia

Monica Dapiaggi, Filippo Maglia, Ilenia Tredici, Beatrice Maroni, Giulio Borghini, Umberto Anselmi Tamburini

PII:

DOI:

S0022-3697(10)00048-X

Reference: doi:10.1016/j.jpcs.2010.03.002 PCS 6111

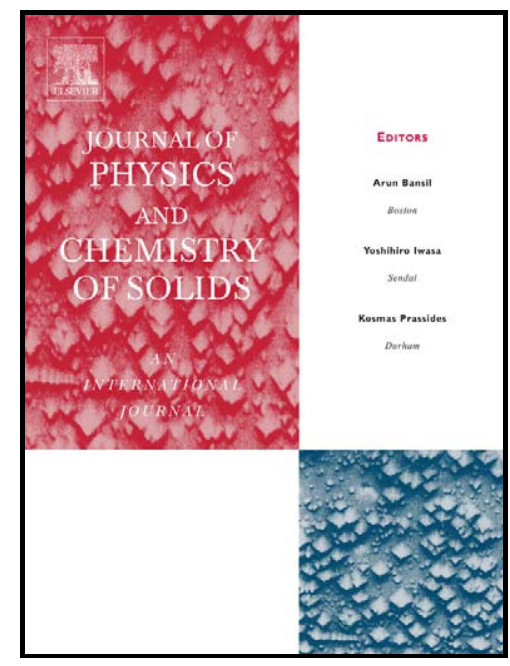

www.elsevier.com/locate/jpcs

To appear in: $\quad$ Journal of Physics and Chemistry of Solids

Cite this article as: Monica Dapiaggi, Filippo Maglia, Ilenia Tredici, Beatrice Maroni, Giulio Borghini and Umberto Anselmi Tamburini, Complex thermal evolution of size-stabilized tetragonal zirconia, Journal of Physics and Chemistry of Solids, doi:10.1016/j.jpcs.2010.03.002

This is a PDF file of an unedited manuscript that has been accepted for publication. As a service to our customers we are providing this early version of the manuscript. The manuscript will undergo copyediting, typesetting, and review of the resulting galley proof before it is published in its final citable form. Please note that during the production process errors may be discovered which could affect the content, and all legal disclaimers that apply to the journal pertain. 


\title{
Complex thermal evolution of size-stabilized tetragonal zirconia
}

\author{
Monica Dapiaggi ${ }^{*}$, Filippo Maglia ${ }^{2}$, Ilenia Tredici ${ }^{2}$, Beatrice Maroni ${ }^{2}$, Giulio \\ Borghini $^{1}$, Umberto Anselmi Tamburini ${ }^{2}$
}

${ }^{1}$ Università degli Studi di Milano, Dipartimento di Scienze della Terra, via Botticelli 23, I20133 Milano,
Italy
${ }^{2}$ Università degli Studi di Pavia, Dipartimento di Chimica Fisica, viale Taramelli 16, I27100 Pavia, Italy

*corresponding author, tel. +39-02-50315605, fax. +39-02-50315597, email:

$\underline{\text { monica.dapiaggi@unimi.it }}$ 


\begin{abstract}
Zirconia nanopowder with doping $\mathrm{YO}_{1.5}$ contents between 0 and $1 \%$ mol. were synthesized by the Pechini method. The crystallite dimensions of the powder, around 10 $\mathrm{nm}$, allows for the size stabilization of the tetragonal polymorph over the thermodynamically stable monoclinic one. As the nanopowders are heated to $1200^{\circ} \mathrm{C}$ and subsequently cooled back to room temperature, a complex evolution of the phase composition occurs. Upon heating the tetragonal phase transforms slowly into the monoclinic one and the transition cannot be completed before entering the stability range of the tetragonal phase (above $1150^{\circ} \mathrm{C}$ ). Upon cooling, on the other hand, the reaction is considerably faster and the complete transformation into the monoclinc phase occurs in a narrow temperature range. Rietveld analysis of the high temperature x-ray patterns revealed as, during heating, the transition is manly controlled by microstructural parameters and in particular it is triggered by the release of RMS microstrain. Upon cooling, on the other hand, the transition is kinetically controlled by the doping content.
\end{abstract}

Keywords:

Nanopowders; Zirconia; Phase transition. 


\section{Introduction}

Zirconium oxide undergoes a transition from its monoclinic to its tetragonal polymorph at around $1175^{\circ} \mathrm{C}$, and from its tetragonal to its cubic polymorph at $2370^{\circ} \mathrm{C}$. The low temperature monoclinic polymorph, the mineral baddeleyite, has very limited practical use, while the two high-temperature polymorphs are employed in a variety of technical applications such as, for instance, solid electrolytes in solid oxide fuel cells and sensors [1]. The stabilization of the tetragonal and cubic phases is traditionally realized by doping with lower valence rare earth oxides. $\mathrm{Y}_{2} \mathrm{O}_{3}$ is most frequently used in the zirconia solid solutions of practical relevance; a minimum amount of $\mathrm{Y}_{2} \mathrm{O}_{3}$ above $2 \%$ mol. and $8 \% \mathrm{~mol}$. is required for the stabilization of the tetragonal and cubic polymorphs respectively. It has been recently shown that tetragonal $\mathrm{ZrO}_{2}$ can also be size-stabilized at room temperature, without doping, provided that the grain size is smaller than a critical value of around $10-40 \mathrm{~nm}$ depending on the synthesis condition adopted [2-9].

Since its discovery by Garvie [2-3], size stabilized zirconia has been the object of numerous studies devoted in particular to the investigation of the mechanism responsible for the inversion of phase stability. Among the possible causes, difference in surface energy between the tetragonal and monoclinic polymorphs is the explanation that received the largest consensus, although the presence of water vapor in crystallite growth, of intrinsic defects, and of lattice and intergranular strain are also believed to play a role [9].

The structural and kinetic aspects concerning the stability of the size stabilized tetragonal zirconia and its transition to the monoclinic polymorph has been investigated although in less detail [10-14]. This transition occurs upon annealing at high 
temperature and is believed to be driven by the grain growth of the tetragonal $\mathrm{ZrO}_{2}$. Many of the investigations concerning this point were performed at room temperature examining samples previously annealed at higher temperatures. The details of the transition mechanism and, in particular, its kinetics were consequently overlooked. Recent studies of pure zirconia [12-13] and on zirconia doped with low amounts of $\mathrm{Sc}_{2} \mathrm{O}_{3}[14]$, revealed as the transition towards the monoclinic phase is kinetically more complex than previously thought. It is completed, in fact, only during the cooling stage, with a transition temperature that depends largely on the thermal history of the sample. Aim of the present study was to investigate, through in-situ X-ray diffraction, the structural and microstructural evolution of $\mathrm{Y}_{2} \mathrm{O}_{3}-\mathrm{ZrO}_{2}$ nanocrystalline solid solutions, with $\mathrm{YO}_{1.5}$ ranging between 0 and $1 \%$ mol., i.e. below the thermodynamic limit for the stabilization of the tetragonal phase, in order to elucidate the role played by the grain size, doping and strain content on the tetragonal to monoclinic transition.

\section{Experimental}

$\mathrm{ZrO}_{2}$ nanopowders with a dopant $\left(\mathrm{YO}_{1.5}\right)$ content ranging between 0 and $1 \%$ at. $\mathrm{Y}$ (i.e. from pure $\mathrm{ZrO}_{2}$ to $\mathrm{Zr}_{0.99} \mathrm{Y}_{0.01} \mathrm{O}_{2-\delta}$ ) were obtained by a modified Pechini method [15]. An aqueous solution containing the proper amounts of Zirconyl (IV) nitrate and yttrium nitrate was mixed with a solution of citric acid in 1:1 (total metal vs citric acid) molar ratio. The solution was then stirred on a hot plate at $80^{\circ} \mathrm{C}$, increasing its viscosity. After a time period that depends on the amount of solution employed, the viscous mass finally turns into a colorless transparent glass. Further heating provided a white solid, which was subsequently ground in a mortar and calcined in a furnace, at $500^{\circ} \mathrm{C}$ for $1 \mathrm{~h}$. 
In-situ high temperature diffraction (an AHT PAP1600 hot chamber was used) patterns were collected in static air, between room temperature and $1200^{\circ} \mathrm{C}$. Data were collected during both heating and cooling stages every $100^{\circ} \mathrm{C}$, the heating rate between each measuring temperature was of $20^{\circ} \mathrm{C}$ per minute.

The hot chamber is attached to a Philips X'Pert $\theta-\theta$ powder diffractometer; data collections were performed on a limited $2 \theta$ range, in order to be able to get the data fast enough to follow the phase transition easily. The range was from 15 to $50^{\circ} 2 \theta$, with a step size of $0.03^{\circ} 2 \theta$ and a counting time of $1 \mathrm{sec}$ per step. The wavelength used is $\mathrm{Cu}$ K $\alpha 1(1.5406 \AA)$, with an incident slit of $1 / 2^{\circ}$, an antiscatter of $12^{\circ}$ on the diffracted beam, and a receiving slit of $0.6 \mathrm{~mm}$, in order to maximize the peak intensity; resolution, on the other hand, was not of primarily concern in our work due to considerable line broadening related to the nano-size of our powder. The sample holder is made of dense alumina, covered with a thin foil of platinum (Goodfellows, 99.9\%), as one of the peaks of $\alpha$-alumina tend to interfere with the main peak of tetragonal $\mathrm{ZrO}_{2}$. The data were analysed with the Rietveld method to obtain the weight percent of the zirconia polymorphs, their cell parameters, and the profile shape analysis. The sample holder peaks were fitted with the Le Bail method [16], in order to remove their influence on the quantitative analysis. The software used was [17-18]. As the small number of peaks collected did not allow any sensible microstructural characterization of the samples during heating, the crystallite size and the RMS microstrain were evaluated from the corresponding Lorentzian components of the peak shape of the modified pseudo-Voigt (function 2 in GSAS), by keeping the Gaussian component (which approximately correspond to the instrumental contribution) fixed at all temperatures. In more details, the crystallite size can be estimated from the LX 
parameter $(\mathrm{D}=\mathrm{LX} / \cos (\theta))$ and the RMS microstrain from the LY parameter $(\mathrm{S}=\mathrm{LY}$ $\tan (\theta))$. This is clearly not the ideal way to operate, especially due to the fact that some strain component varies with the diffraction angle in a way which is similar to the Caglioti/Gaussian component.

\section{Results and discussion}

Three different samples were analyzed with dopant $\left(\mathrm{YO}_{1.5}\right)$ content equal to $0 \%$ (nominal composition: $\mathrm{ZrO}_{2}$, hereafter $\mathrm{Zr} \_0$ ), $0.5 \%$ (nominal composition:

$\mathrm{Zr}_{0.995} \mathrm{Y}_{0.005} \mathrm{O}_{2-\delta}$, hereafter $\mathrm{Zr} \_05$ ), and 1\% (nominal composition: $\mathrm{Zr}_{0.99} \mathrm{Y}_{0.01} \mathrm{O}_{2-}$

$\delta$, hereafter $\mathrm{Zr} \_$1). The synthetic route employed in this study is well known to produce oxides with crystallite and grain sizes in the nanometric range; the crystallite/grain size of the as-synthesized material is generally dependent on the annealing treatment. The latter is necessary to promote the crystallization of the oxide phase, initially obtained in amorphous form, and to remove the organic residuals. On the basis of DTA-DSC and $\mathrm{XRD}$ analyses the starting material has been in this case annealed at $500^{\circ} \mathrm{C}$ for $1 \mathrm{~h}$. Structural and microstructural characterization of the starting powders was performed, using the software MAUD [19], using high quality datasets collected at ESRF (ID31) during the experiment HS3654. These high energy patterns, with a wavelength of about $0.4 \AA$, allowed indeed a much better accuracy, in particular for what concerns the microstructural parameters evaluation, since the reciprocal lattice could be explored in much higher detail.

The results of this analysis are shown in Table 1. All the samples were free of monoclinic polymorph indicating that the synthetic procedure adopted was successful in the stabilization of the high temperature tetragonal polymorph. The cell volume 
increases with the doping content coherently with the larger size of the $\mathrm{Y}^{3+}$ ion with respect to $\mathrm{Zr}^{4+}$. The $\mathrm{Zr} \_0$ and $\mathrm{Zr} \_05$ showed comparable values of crystallite size (around $12 \mathrm{~nm}$ ) while $\mathrm{Zr}$ _ 1 showed a slightly smaller value. The grain size is for all the prepared samples below the previously reported limit for the complete stabilization of the tetragonal phase in the pure $\mathrm{ZrO}_{2}$. Although there is some scatter in the literature about this limit, values between 10 and $40 \mathrm{~nm}$ are generally reported. No data are available in the literature for the $\mathrm{Zr} \_05$ and $\mathrm{Zr} \_1$ compositions as no previous reports on these compositions are at hand. The RMS microstrain variation was on the other hand more significative; the RMS microstrain value for the Zr_05 sample was approximately twice that of the $\mathrm{Zr} \_1$.

Figure 1 shows the qualitative evolution of the HT-XRD pattern collected during the heating (upper part) and cooling (lower part) cycles on the $\mathrm{Zr} \_0$ sample. The onset of the formation of the monoclinic polymorph is clearly visible at temperatures above $600^{\circ} \mathrm{C}$. As the temperature is further increased the amount of the monoclinic phase increases up to above $50 \%$ at $1100^{\circ} \mathrm{C}$; at $1200^{\circ} \mathrm{C}$ the tetragonal polymorph returns to be the only phase present as at this temperature the tetragonal phase becomes thermodynamically stable. Similar qualitative trends were observed also for the other two compositions. Upon cooling, as the temperature is reduced below $700-800^{\circ} \mathrm{C}$, the monoclinic fraction reaches values above $95 \%$; finally, at room temperature no residual tetragonal $\mathrm{ZrO}_{2}$ could be observed.

The data collected at each temperature were analyzed using the Rietveld method, in order to obtain a quantitative evaluation of the phase composition during heating and cooling. An example of a Rietveld fit is reported in Figure 2. Figure 3 shows the quantitative analysis at each temperature, in terms of the monoclinic polymorph wt.\%, 
during heating (continuous lines) and cooling (dotted lines), that allows a direct comparison among the three samples.

The transition is clearly different during the heating and the cooling stages. Upon cooling the transformation kinetic is completed within a narrower temperature interval $\left(<\right.$ than $100^{\circ} \mathrm{C}$ ) and the onset temperature for the tetragonal to monoclinic transition decreases going from $\mathrm{Zr} \_0$ to $\mathrm{Zr}$ _. This indicates, as expected, a larger stability field for the tetragonal phase increasing the doping content. This behavior, that follows the well known behavior for "conventional" microcrystalline sample, was expected as, at the end of the heating cycle, grain coarsening goes well above the limit for any size stabilizing effect.

The situation is indeed more complex during the heating cycle. Not only, in fact, the kinetics is much more shallow, with only about $50 \%$ of the tetragonal phase that transforms into the monoclinic one within a $600-700^{\circ} \mathrm{C}$ temperature interval, but also the temperature for the transformation onset does not follow the doping content, being the $\mathrm{Zr} \_05$ sample the first to initiate the transition at $\sim 400^{\circ} \mathrm{C}$ and the $\mathrm{Zr} \_1$ the last one at a temperature of $\sim 600^{\circ} \mathrm{C}$.

During the heating cycle, the transition is more likely to occur under microstructural control. Size stabilization is in fact expected to play the leading role, since the doping contents employed are well below the minimum limit for the stabilization of the tetragonal phase.

A qualitative insight on the evolution of the microstructure during the heating cycle can be gained from Figure 1 (upper part) by observing the peak shape evolution of the tetragonal polymorph. As expected, a shrinkage in the width of the peaks of the tetragonal phase is observed as the temperature is increased. Figure 4 shows the trend 
of the Lorentzian peak width at $29.9^{\circ}$, as a function of the annealing temperature, for the three compositions. For all $\mathrm{YO}_{1.5}$ contents the shrinkage of the diffraction peak begins at an almost identical temperature of around $400^{\circ} \mathrm{C}$ and than proceeds with a slope that is somewhat less pronounced for the $\mathrm{Zr} \_1$ sample than for the other two.

In the vast majority of the literature, the width of the main diffraction peak is used for a straight estimation of the crystallite size using the Scherrer formula. The temperature evolution of the phase composition of nanocrystalline pure zirconia has been therefore justified, in most cases, solely on the basis of the grain coarsening. If applied to our results, where for the first time different low doping contents are taken into account, such interpretative model is clearly not sufficient to justify the experimental evidences. The negligible difference in the initial grain size for the three compositions (Table 1) and the results of figure $\mathbf{4}$ cannot justify the clear differences in the onset temperature for the phase transition.

To clarify this point an evaluation of the RMS microstrain has been performed for all the samples at the different annealing temperatures (heating cycle). The separation of crystallite size and of the RMS microstrain contribution to the Lorentzian peaks was, differently from the case of the high quality synchrotron data of Table 1, possible in a more approximate way, as we are using a smaller 2 theta range for our analyses. For that reason it was chosen to show the RMS microstrain results only as variations with respect to the more precise starting values of Table 1.

The results are shown in Figure 5: the relationship between the RMS microstrain and the onset temperature for the phase transition (see Figure 3) is evident. The $\mathrm{Zr} \_05$, characterized by the initial highest value of microstrain, starts to release the microstrain at the lowest temperature which also corresponds to the beginning of the monoclinic 
phase formation. Subsequently, at progressively higher temperature, the same behavior is followed by the $\mathrm{Zr} 0$ and finally the $\mathrm{Zr} 1$ sample, suggesting that microstrain release is the process responsible for the initiation of the phase transformation at low temperature.

\section{Conclusions}

The thermal behavior of zirconia nanopowders with low yttria contents was investigated by in-situ high temperature XRD. All starting materials were characterized by a doping content well below the thermodynamic limit for the stabilization of the tetragonal phase. The tetragonal phase was on the other hand stabilized thanks to the reduced dimension of the grain size. Room temperature XRD measurements showed as all sample had a crystallite size around $10 \mathrm{~nm}$ while the RMS microstrain content varied for the different doping contents.

Upon heating the size-stabilized tetragonal phase transforms partially into the monoclinic one. The onset temperature for this transformation is strongly dependent on the RMS microstrain content and occurs at the temperature where the material starts releasing its stress content. The transition to the monoclinc phase cannot be completed upon heating before entering, at $1200^{\circ} \mathrm{C}$ the stability range of the tetragonal form. On the other hand, once the grain size is increased as an effect of annealing, the materials rapidly transforms into the monoclinic phase cooling down from from $1200^{\circ} \mathrm{C}$ to room temperature. The onset temperature of the transition is in this case dependent on the doping content. 


\section{References}

[1] R. Stevens, An introduction to zirconia; Twickenham, England, Magnesium

Elektron Ltd.: 1983; pp 1-22.

[2] R.C. Garvie, J. Phys. Chem. 69 (1965) 1238-1243.

[3] R.C. Garvie, J. Phys. Chem. 82 (1978) 218-224.

[4] N-L. Wu, T-F. Wu, I.A. Rusakova, J. Mater. Res. 16 (2001) 666-669.

[5] T. Schmidt, M. Mennig, H. Schmidt, J. Amer. Ceram. Soc. 90 (2007) 1401-1405.

[6] S. Shukla, S. Seal, R. Vij, S. Bandyopadhyay, Z. Rahman, Nanoletters 2 (2002) 989993.

[7] J.Ch. Valmalette, M. Isa, Chemistry of Materials. 2002, 14, 5098-5102.

[8] Y.L. Zhang, X.J. Jin, Y.H. Ronga, T.Y. Hsu (Xu Zuyao), D.Y. Jiang, J.L. Shi

Mater. Sci. Eng. A 438-440 (2006) 399-402

[9] M.W. Pitcher, S.V. Ushakov, A. Navrotsky, B.F. Woodfield, G. Li, J. Boerio-Goates

B.M. Tissue, J. Amer. Ceram. Soc. 88 (2005) 160-167.

[10] S. Tsunekawa, S. Ito, Y. Kawazoe Nanoletters 3 (2003) 871-875

[11] S. Shukla, S. Seal, J. Phys. Chem. B 108 (2004) 3395-3399.

[12] M. Bhagwat, V. Ramaswamy, Mater. Res. Bull. 39 (2004) 1627-1640.

[13] E. Djurado,1 P. Bouvier, G. Lucazeau, J. Solid State Chem. 149 (2000) 399-407

[14] G. Xu, Y-W. Zhang, C.-S. Liao, C.-H. Yan, Phys. Chem. Chem. Phys. 6 (2004) $5410-5418$.

[15] M.P. Pechini, U.S. Patent No. 3330697 (1967).

[16] A. Le Bail, H. Duroy, J.L. Fourquet, Mater. Res. Bull. 23 (1988) 447-452.

[17] C. Larson, R.B. Von Dreele, General Structure Analysis System (GSAS); Los

Alamos National Laboratory: Los Alamos, NM, 1994; pp 86-748.

[18] B.H.J Toby, Appl. Crystall. 34 (2001) 210.

[19] L. Lutterotti, S. Gialanella, Acta Mater. 46 (1998) 101. 


\section{Figures captions}

Figure 1. In-situ high temperature XRD patterns for the Zr_0 sample. Upper part: heating cycle, lower part: cooling cycle.

Figure 2. Example of a Rietveld fit of the $\mathrm{Zr} \_05$ sample at $800^{\circ} \mathrm{C}$.

Figure 3. Quantitative analyses of monoclinic polymorph as a function of temperature on the heating (solid lines) and on the cooling (dotted lines) stages.

Figure 4. Thermal evolution of the peak shape and of the monoclinic polymorph during the heating stage.

Figure 5. Thermal evolution of the RMS during the heating stage. 


\section{Tables}

Table 1 - Structural and microstructural parameters of the as-prepared powders.

\begin{tabular}{|l|l|l|l|}
\hline Sample & $<\mathrm{D}>\mathrm{V}(\mathrm{nm})$ & RMS strain $\left(10^{-3}\right)$ & Cell volume $\left(\AA^{3}\right)$ \\
\hline $\mathrm{Zr} 0$ & $12.2(2)$ & $4.18(1)$ & $67.006(4)$ \\
\hline $\mathrm{Zr} 0.5$ & $12.7(1)$ & $5.97(4)$ & $67.037(4)$ \\
\hline $\mathrm{Zr} 1$ & $9.81(3)$ & $2.91(6)$ & $67.043(6)$ \\
\hline
\end{tabular}




\section{Figures}
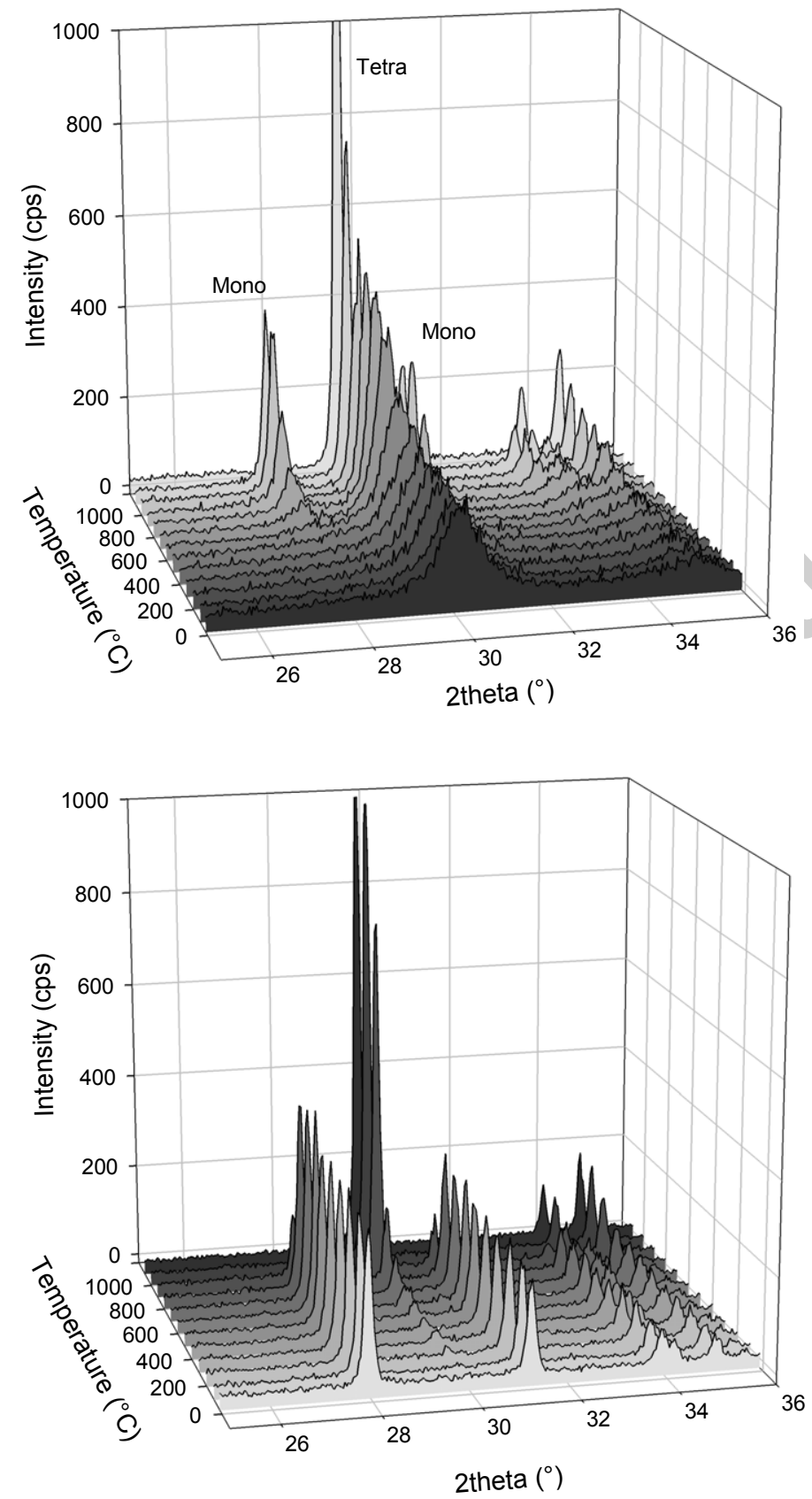

Figure 1. In-situ high temperature XRD patterns for the $\mathrm{Zr}$ _0 sample. Upper part: heating cycle, lower part: cooling cycle. 


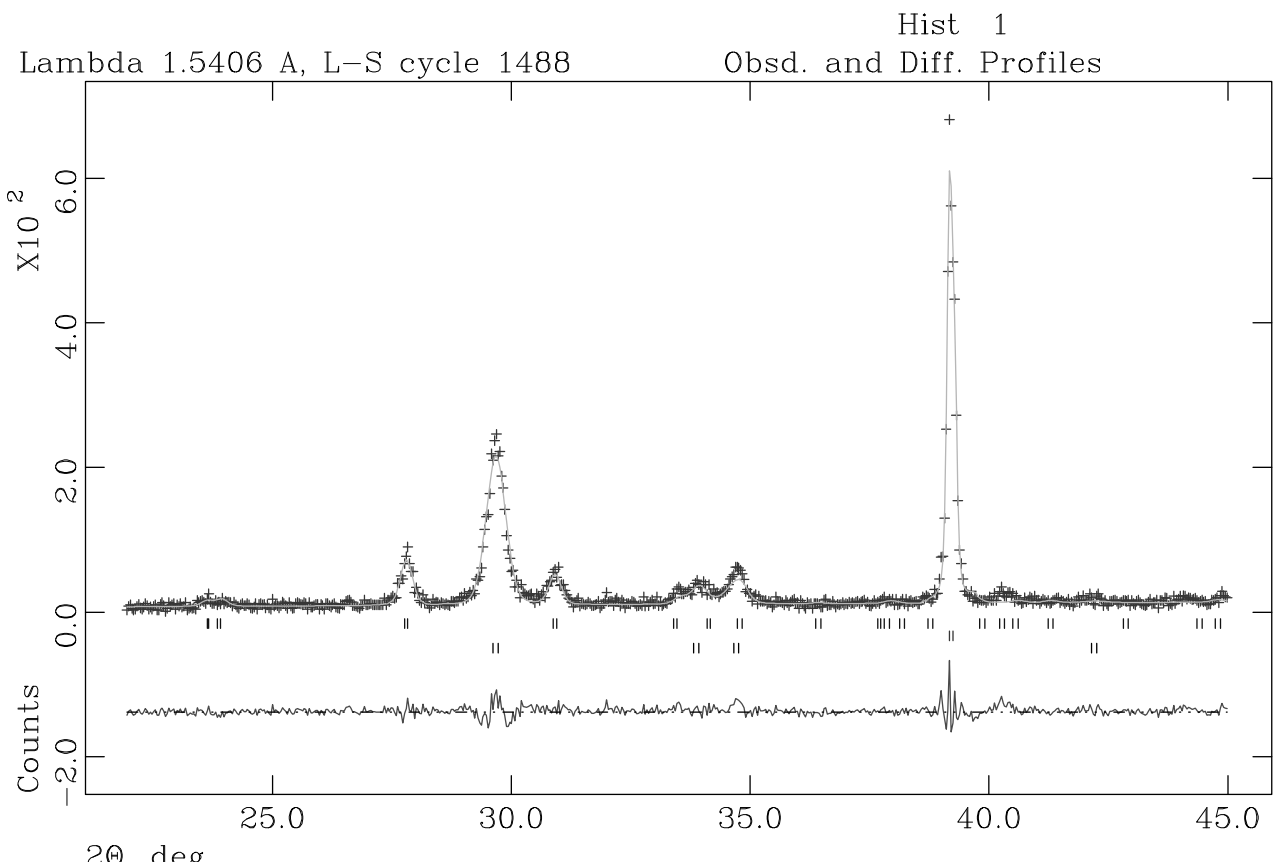

Figure 2: Example of a Rietveld fit of the $\mathrm{Zr} \_05$ sample at $800^{\circ} \mathrm{C}$. 


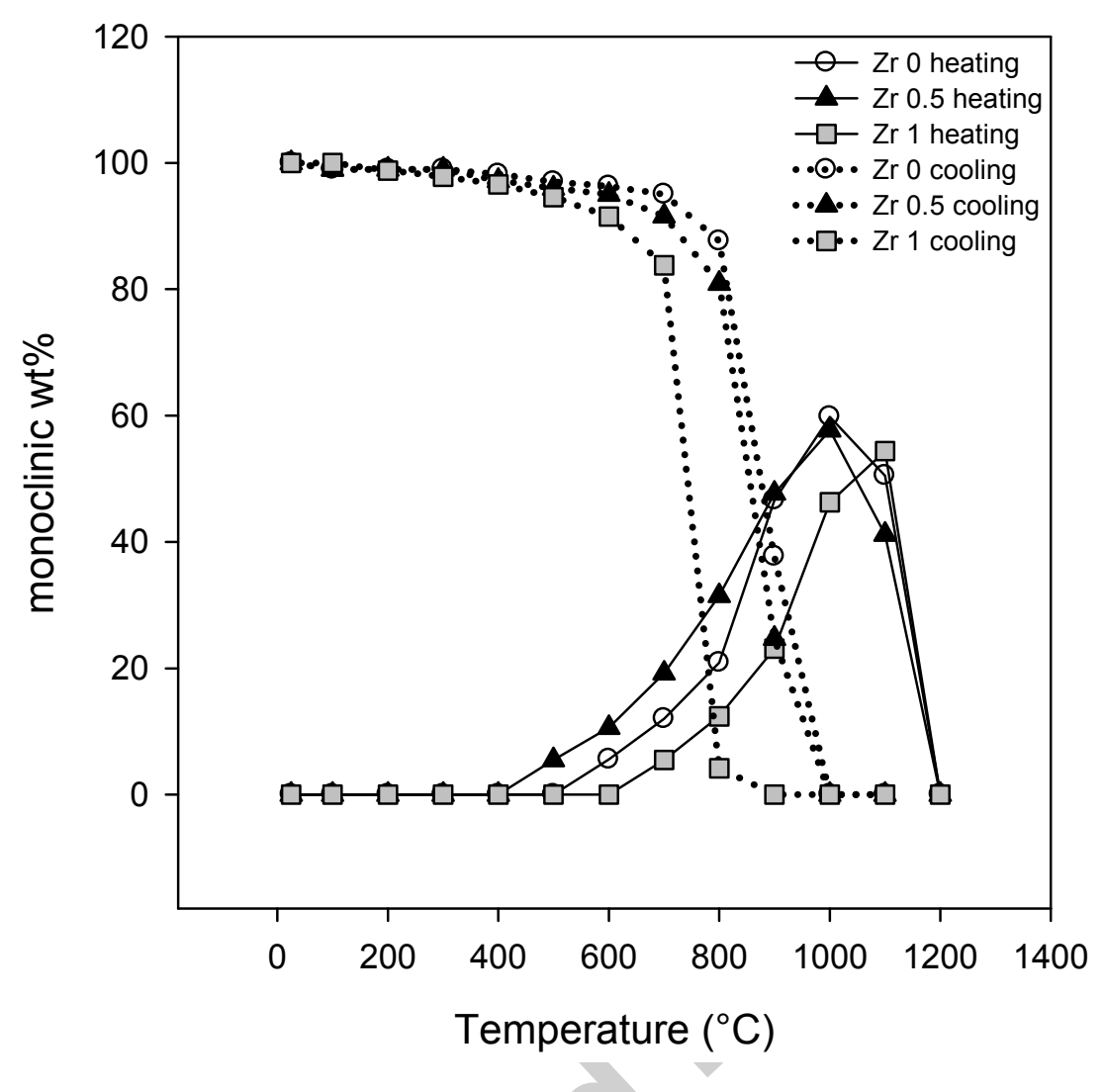

Figure 3. Quantitative analyses of monoclinic polymorph as a function of temperature on the heating (solid lines) and on the cooling (dotted lines) stages. 


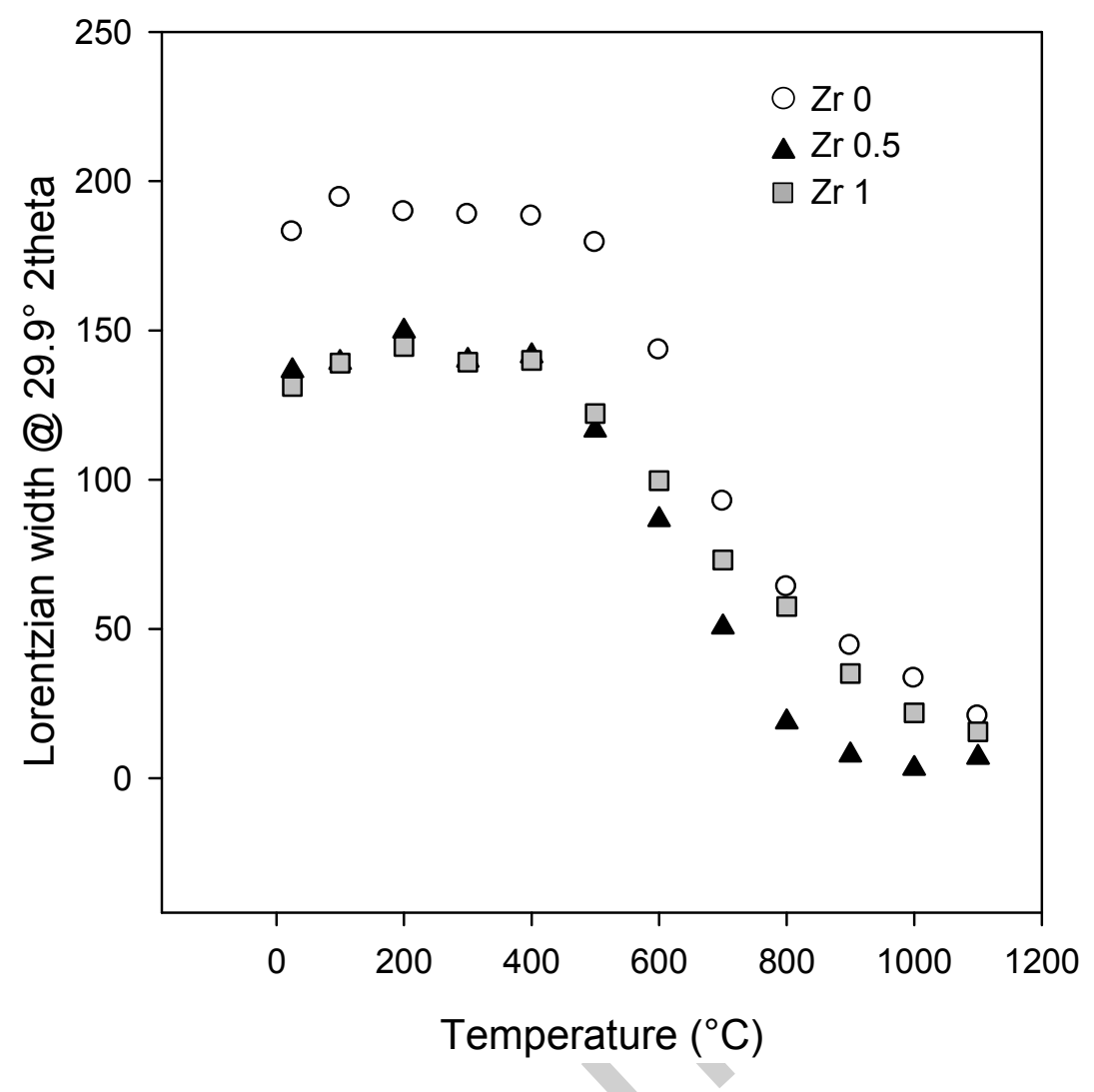

Figure 4. Thermal evolution of the peak shape and of the monoclinic polymorph during the heating stage. 


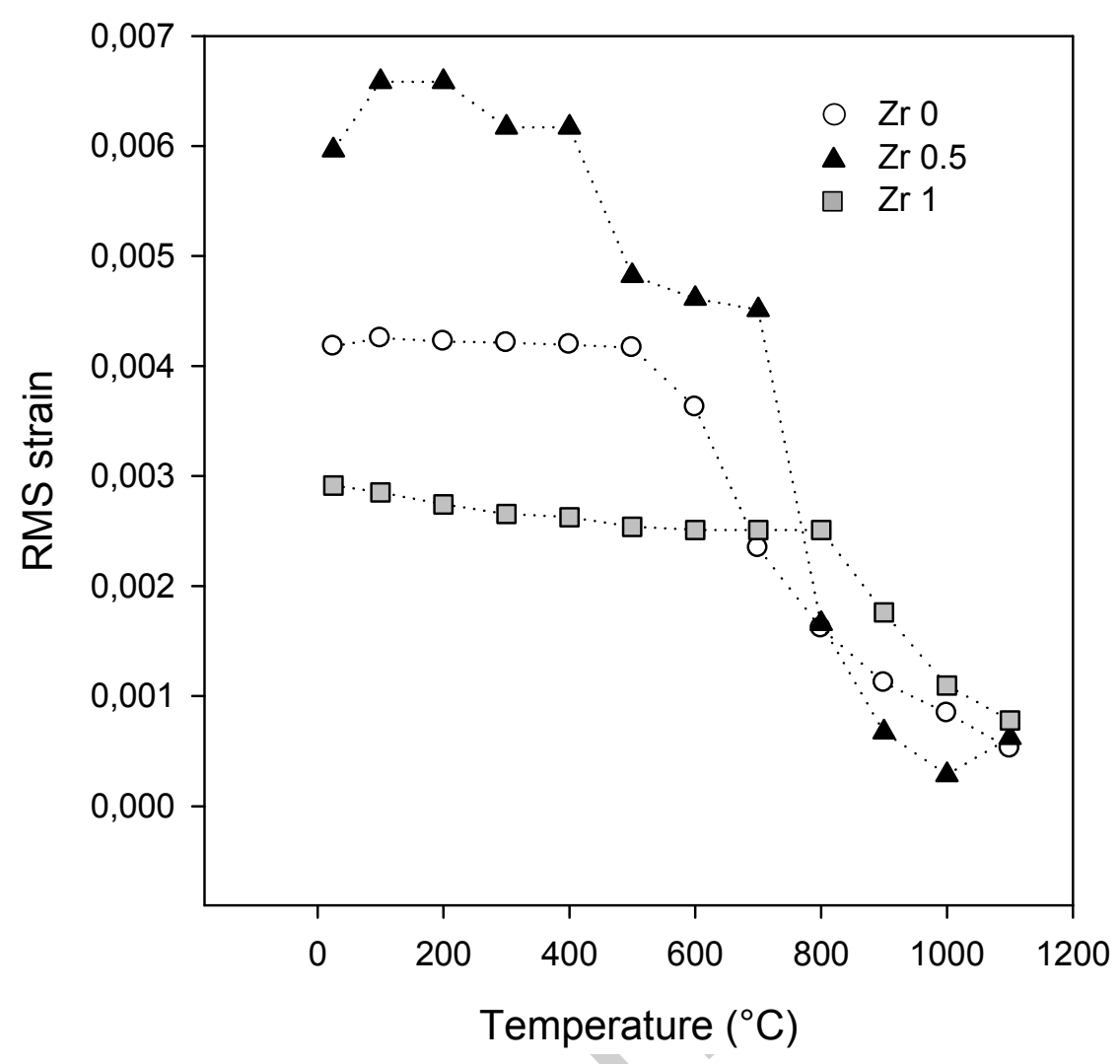

Figure 5. Thermal evolution of the RMS during the heating stage. 


\section{Acknowledgements}

The authors would like to thank ESRF for providing beam time (experiment HS3654), and the staff at ID31, in particular Michela Brunelli and Andy Fitch for their help during data collection. Fondazione Cariplo is thanked for funding. 